OPEN ACCESS

Edited by:

Nicholas Syn,

National University of Singapore,

Singapore

Reviewed by:

Mettu Srinivas Reddy,

Gleneagles Global Health City, India

Ning Qi Pang,

National University Health System,

Singapore

Volkan Ince,

Inönü University, Turkey

${ }^{*}$ Correspondence:

Wei Dong

tj_dongwei@126.com

Specialty section: This article was submitted to

Surgical Oncology,

a section of the journal

Frontiers in Oncology

Received: 06 April 2021

Accepted: 06 May 2021

Published: 27 May 2021

Citation:

Zhang E-I, Cheng Q, Huang Z-y and Dong W (2021) Revisiting Surgical Strategies for Hepatocellular Carcinoma With Microvascular Invasion.

Front. Oncol. 11:691354. doi: 10.3389/fonc.2021.691354

\section{Revisiting Surgical Strategies for Hepatocellular Carcinoma With Microvascular Invasion}

\author{
Er-lei Zhang ${ }^{1,2}$, Qi Cheng ${ }^{1,2}$, Zhi-yong Huang ${ }^{1,2}$ and Wei Dong ${ }^{1,2 *}$ \\ 1 Hepatic Surgery Center, Tongji Hospital, Tongji Medical College Huazhong University of Science and Technology, \\ Wuhan, China, 2 Key Laboratory of Organ Transplantation, Chinese Academy of Medical Sciences, Wuhan, China
}

Although liver resection (LR) and liver transplantation $(\mathrm{LT})$ are widely considered as potentially curative therapies for selected patients with hepatocellular carcinoma (HCC); however, there is still high risk of tumor recurrence in majority of HCC patients. Previous studies demonstrated that the presence of microvascular invasion (MVI), which was defined as the presence of tumor emboli within the vessels adjacent to HCC, was one of the key factors of early HCC recurrence and poor surgical outcomes after LR or LT. In this review, we evaluated the impact of current MVI status on surgical outcomes after curative therapies and aimed to explore the surgical strategies for HCC based on different MVI status with evidence from pathological examination. Surgical outcomes of HCC patients with MVI have been described as a varied range after curative therapies due to a broad spectrum of current definitions for MVI. Therefore, an international consensus on the validated definition of $\mathrm{MVI}$ in $\mathrm{HCC}$ is urgently needed to provide a more consistent evaluation and reliable prediction of surgical outcomes for HCC patients after curative treatments. We concluded that MVI should be further sub-classified into MI (microvessel invasion) and MPVI (microscopic portal vein invasion); for HCC patients with MPVI, local RO resection with a narrow or wide surgical margin will get the same surgical results. However, for HCC patients with MI, local surgical resection with a wide and negative surgical margin will get better surgical outcomes. Nowadays, MVI status can only be reliably confirmed by histopathologic evaluation of surgical specimens, limiting its clinical application. Taken together, preoperative assessment of MVI is of utmost significance for selecting a reasonable surgical modality and greatly improving the surgical outcomes of HCC patients, especially in those with liver cirrhosis.

Keywords: microvascular invasion, hepatocellular carcinoma, liver resection, liver transplantation, surgical strategy, sub-classification

\section{INTRODUCTION}

Hepatocellular carcinoma (HCC) is one of the most common malignancies and ranks the third most frequent causes of cancer-related death worldwide (1). China alone accounts for more than half of the new cases in the world (2). Liver resection (LR) and liver transplantation (LT) remain as the first-choice treatments for patients with early-stage HCC. Unfortunately, more than 50\% of HCC patients 
experience recurrence within 5 years after curative treatments, contributing to an increase in the number of tumor-related deaths (3-5). In previous studies, microscopic vascular invasion (MVI), which was always defined as tumor cells invaded to the microscopic vessels in the surrounding liver tissues contiguous to the tumor, had been demonstrated as a strong risk factor associated with tumor recurrence and poor overall survival (OS) among HCC patients after LR or LT (6-15). In addition, MVI was considered as one of the most important prognostic factors within the $\mathrm{T}$ criteria in the 8th edition of the American Joint Committee on Cancer (AJCC) staging system (16). However, because of the wide spectrum of current definitions of MVI, other studies indicated that MVI did not affect the long-term surgical outcomes after curative therapies for HCC patients, especially for those with early-stage HCC (17-19). The effect of MVI on long-term surgical outcomes is still in debate. In order to improve surgical outcomes, anatomic resection (AR, complete removal of tumor-bearing portal territory) and wide surgical margin were pursued by liver surgeons, which could theoretically improve the "radical cure" of tumors and decrease the tumor recurrence rates. However, the comparison of clinical efficacy between AR and non-anatomic resection (NAR) had been discussed in the past few decades, making it more clear of their indication based on tumor biological features and underlying liver cirrhosis, but yet needed to be completed. For HCC patients with MVI, how to select these surgical techniques remains unclear. Some studies stressed the importance of the surgical margin width, arguing that AR was not necessary when a wide $(\geq 1 \mathrm{~cm})$ surgical margin can be attained $(20,21)$. For HCC patients with MVI, wide surgical margin will improve long-term surgical outcomes after LR $(9,22)$. A recent study indicated that $A R$ with a negative $0-\mathrm{cm}$ surgical margin was not associated with poor OS compared with a negative and wide surgical margin. On the contrary, NAR with a negative 0 -cm margin was associated with worse surgical outcomes, suggesting that wide surgical margin should be necessary in HCC patients receiving NAR (23). Up to now, MVI can only be precisely evaluated by histopathologic examination of surgical specimens which limited its clinical application. However, with increasing recognition of MVI and its prognostic value on surgical outcomes of HCC, preoperative MVI prediction systems for surgical decision making have become a hot topic in recent researches. In recent years, some studies have reported the possibility of imaging findings to predict the MVI of HCC (24-27). However, it still has a limited capacity to detect MVI and the precise detection of MVI needs further histological identification (28). This review aims to investigate the impact of current MVI status on surgical outcomes after curative therapy and sheds new light on the surgical strategies for HCC based on different MVI status with evidence from pathological examination.

\section{THE DEFINITION AND SUB-CLASSIFICATION OF MVI}

MVI is a histological feature, and it is acknowledged as tumor cells invading into a portal vein, hepatic vein, or a large capsular vessel of the surrounding hepatic tissues, partially or totally lined by endothelial cells visible only by microscopy (11). Previous studies indicated that the incidence of MVI in HCC patients ranged from $15 \%$ to $74.4 \%(6,29,30)$, and its incidence was positively associated with increasing size of HCC, suggesting that tumor size was an important predictive factor for MVI (31). This wide difference is partly explained by the selection bias of included patients and varied definition of MVI in HCC. MVI includes a wide spectrum, ranging from invasion of a single small vessel around the tumor capsule to micro-portal vein invasion (6). With increasing recognition of MVI and its prognostic value on surgical outcomes, preoperative MVI prediction models for surgical decision making in HCC have become a hot topic in recent years $(10,11,32)$. However, due to the broad range of current definitions for MVI, one would also expect a varied range of surgical outcomes in HCC patients with MVI undergoing LR or $\operatorname{LT}(7,31,33,34)$.

In the past few years, several studies had attempted to put forward MVI classifications according to the number of invaded vessels, number of tumor cells, distance of invaded vessel to tumor edge and subtypes of invaded vessels (10, 35-40). In the practical guidelines for the pathological diagnosis of HCC developed by China (35), the presence of MVI was recommended to be evaluated in all tissue sections and graded according to the risk stratification based on the number and distribution as follows: no MVI; low-risk (M1): $<5$ MVI and $\leq 1 \mathrm{~cm}$ away from the tumor tissues; and high-risk (M2): $>5 \mathrm{MVI}$ or $>1 \mathrm{~cm}$ away from the tumor tissues. Roayaie et al. (10) proposed a novel classification of MVI in HCC patients, which included invasion of a vessel with a muscular wall and a vessel invasion that was more than $1 \mathrm{~cm}$ away from the tumor tissues. Sumie et al. (39) sub-classified MVI into three grades according to the number of vessels invaded: no vascular invasion (NVI), mild MVI (1-5 vessels), and severe MVI ( $>5$ vessels). Another study from China sub-classified MVI into non-MVI, low-MVI (the number of invaded vessels $\leq 5$, the number of invaded carcinoma cells $\leq 50$ and the distance of invasion from tumor edge $\leq 1 \mathrm{~cm}$ ) and high-MVI (the number of invaded vessels $>5$, the number of invaded carcinoma cells $>50$ and the distance of invasion from tumor edge $>1 \mathrm{~cm}$ ) (38). This classification was similar with a study from Japan (40). Nonetheless, the definitions of MVI in these sub-classification systems were obscure. They defined MVI as follows: clusters of tumor cells were observed in the portal vein accompanied with hepatic artery and bile duct in the portal tract, and clusters of tumor cells in the vessels in fibrous capsule of HCC were also defined as MVI (40). In addition, these classification systems were relatively complicated to generalize in real pathologic circumstances and had not been revalidated in other research. A summary of the current MVI classification had been summarized by Erstad and colleagues (41). A recent study by Kang et al. (7) suggested that MVI in excised specimens should be further sub-classified into microvessel (which was defined as newly developed microvascular structures in the tumor capsule or fibrotic peritumoral non-tumor liver, these microvessels were not portal veins, hepatic veins or hepatic arteries) invasion (MI) and microscopic portal vein invasion (MPVI). Their results 
indicated that MPVI was associated with more aggressive clinicpathologic features and poorer surgical outcomes compared with HCC patients with MI. Therefore, they recommended that the original MVI classification should be divided into MI and MPVI and it needed further research to validate their findings. However, the number of surgical specimen slides of examined and surgical types also affect the assessment of MVI and inadequate specimen may induce a false-negative evaluation $(40,42)$. In this regard, it is urgent to establish a universal criterion for the pathological and clinical study of MVI.

\section{AND SURGICAL OUTCOMES}

\section{Liver Resection (LR)}

MVI is widely acknowledged as an expression of aggressive biological behavior of HCC, and is currently one of the most critical factors associated with adverse prognosis after curative resection. The 5-year Disease Free Survival (DFS) rate ranges from $7.5 \%$ to $48 \%$ and the corresponding 5 -year OS rate is $38.4 \%$ to $66 \%$ in HCC patients with MVI $(7,9,14,22,31,33,34,43-47)$. The reasons for this broad range may be due to a lack of consensus on the definition of MVI and selected patients with different tumor size in the above studies. Although there is an agreement in the definition of MVI on some histologic features, such as the presence of tumor cells in portal vessels, large vessels of the fibrotic capsule, there are still some controversies in other aspects, such as the distance from the invaded vessels to the edge of tumor, the number of invaded vessels (6). It remains unclear which biological features are the most important factors for surgical prognosis. In this review, we allow the different definitions of MVI and aim to evaluate the impact of MVI status on surgical outcomes. HCC patients with MVI have been demonstrated to have a wide range of surgical outcomes. A metaanalysis analyzed 1501 HCC patients undergoing LR, and addressed the prognostic impact of MVI on surgical outcomes, the results indicated that the presence of MVI reduced their 5year DFS rates $(\mathrm{RR}=1.51$ [1.29-1.77]) (6). A study reported that stage II HCC patients (based on TNM stage) with MVI had similar surgical outcomes compared with stage III HCC patients without MVI, which demonstrated that MVI was a more important factor which affected tumor recurrence and longterm survival (median, OS 4.3 vs 3.9 years, $p=0.622$ ) (48). Other studies indicated that HCC patients with MVI had lower RFS and OS rates than those without MVI even for patients with solitary HCC $\leq 2 \mathrm{~cm}(49,50)$. Sumie et al. (39) evaluated whether the classification of MVI based on number of invaded vessels affected tumor recurrence and survival after surgical resection for HCC patients. MVI were stratified into no MVI, mild MVI and severe MVI groups and the DFS rates at 2 years were $75.9 \%$, $47.2 \%$, and $32.7 \%$, respectively $(p<0.05)$. The corresponding OS rates at 5 years were $91.5 \%, 70.4 \%$, and $51.4 \%$, respectively $(p<$ $0.05)$ (39). However, the classification was difficult to apply in clinical practice due to complex histological examination. A recent study sub-classified HCC patients with MVI into MI and MPVI group. Their results indicated that both MI and
MPVI were independent prognostic factors for DFS and OS after LR. The 5-year DFS rates were $75 \%, 45 \%$, and $25 \%$ in the NVI, MI, and MPVI groups, respectively $(p<0.001)$, whereas the corresponding 5-year OS rates were $90 \%, 78 \%$, and $55 \%$, respectively $(p<0.001)$ in HCC patients undergoing LR (7). In HCC patients, the spread of tumor cells via a portal vein has generally been accepted as the main mechanism for intrahepatic metastasis $(10,51)$. This mechanism indicated the progress of tumor invasion from MI to MPVI. Accordingly, MPVI showed a higher frequency of early recurrence within 1 year and extrahepatic recurrence than MI (7). Unfortunately, in this study, the authors did not analyze the impact of AR and surgical margin status on the surgical outcomes with MI or MPVI. Studies that assessed the prognostic significance of MVI for long-term outcomes after LR are summarized in Table $\mathbf{1 .}$

\section{Liver Transplantation}

Liver transplantation (LT) is generally accepted as the first-line treatment for selected HCC patients for the reason of removing the entire tumor and underlying liver disease. Especially, the severity of cirrhosis at risk for the development of de novo HCC is removed (52). Waitlist priority for a LT in America and Europe follows the "sickest-first" principle: decompensated cirrhosis and HCC (53). In order to limit LT to those with poor post-LT outcomes, HCC waitlist priority has mainly relied on two criteria: Milan criteria (solitary tumor $<5 \mathrm{~cm}$ or up to three nodules and each $<3 \mathrm{~cm}$ in size, without major vascular invasion) and University of California-San Francisco (UCSF, solitary tumor of $6.5 \mathrm{~cm}$, or three nodules with the largest diameter of $4.5 \mathrm{~cm}$ and a total tumor diameter of $8 \mathrm{~cm}$ ) criteria, to exclude those with high risks of tumor recurrence $(54,55)$. Studies indicated that HCC patients within the Milan and UCSF criteria had equivalent survival rates and recurrence rates, and surgical outcomes were comparable for MVI-negative patients within or beyond Milan criteria (3.3\% versus 4.7\%) (13, 56). Accordingly, based on these surveys, LT for HCCs beyond the Milan criteria was an acceptable and life-saving method. Since the high cost, long waiting times on the waiting list of LT, coupled with the allograft shortage, it is of great importance to allocate donor livers to HCC patients with the best opportunity for long-term surgical outcomes.

It is widely accepted that MVI is one of the most important risk factors for tumor recurrence and poor OS among HCC patients within transplantation criteria after LT (7, 33, 36, 57-64). By defining MVI as tumor cells were present within the lumens of veins microscopically, Nitta et al. (33) recently compared the surgical outcomes after LT for MVI-positive HCC patients ( $\mathrm{n}=$ $134)$ and MVI-negative HCC patients $(n=238)$. The 5-year OS rates were $60.9 \%$ and $89.9 \%$, respectively $(p<0.001)$, the corresponding 5-year DFS rates were $51.4 \%$ and $80.6 \%$, respectively $(p<0.001)$. A meta-analysis of 2003 HCC patients who underwent LT indicated that MVI was related to 2.3-fold decrease of 5-year OS rate compared with those without MVI (6). Therefore, MVI was the most common factor used in risk stratification and surveillance for HCC recurrence after LT (65). Bhatti et al. (66) indicated that the estimated 4-year RFS rate in patients with combined AFP > $600 \mathrm{ng} / \mathrm{ml}$ and MVI was $0 \%$ after 
TABLE 1 | MVI prognostic capability in HCC after liver resection.

\begin{tabular}{|c|c|c|c|c|c|c|c|c|}
\hline Author & Vascular type & MVI status & Number & 5-year OS (\%) & $p$-value & 5-year DFS (\%) & $p$-value & Published year \\
\hline \multirow[t]{3}{*}{ Kang et al. (7) } & $\mathrm{Ml}+\mathrm{MPVI}$ & $\mathrm{NVI}$ & 212 & 90 & 0.001 & 75 & $<0.001$ & 2020 \\
\hline & & $\mathrm{Ml}$ & 64 & 78 & & 45 & & \\
\hline & & MPVI & 36 & 55 & & 25 & & \\
\hline \multirow[t]{2}{*}{ Song et al. (43) } & Ml+MPVI+MHVI & $\mathrm{NVI}$ & 206 & NA & NA & 49.3 & $<0.001$ & 2019 \\
\hline & & MVI & 94 & NA & & 28.2 & & \\
\hline \multirow[t]{2}{*}{ Wang et al. (34) } & $\mathrm{Ml}+\mathrm{MPVI}+\mathrm{MHVI}$ & $\mathrm{NVI}$ & 34 & 78.3 & $<0.001$ & 45.7 & $<0.001$ & 2019 \\
\hline & & MVI & 30 & 48.9 & & 7.5 & & \\
\hline \multirow[t]{2}{*}{ Nitta et al. (33) } & $\mathrm{Ml}+\mathrm{MHVI}$ & $\mathrm{NVI}$ & 148 & 66.1 & $<0.001$ & 28.6 & $<0.001$ & 2019 \\
\hline & & $\mathrm{MVI}$ & 117 & 38.4 & & 15.8 & & \\
\hline \multirow[t]{2}{*}{ Han et al. (9) } & NA & NVI-N* & 145 & 64 & $<0.05$ & 41 & $<0.05$ & 2018 \\
\hline & & MVI-N* & 158 & 55 & & 30 & & \\
\hline \multirow[t]{2}{*}{ Han et al. (9) } & NA & NVI-W" & 300 & 78 & $<0.01$ & 58 & $<0.01$ & 2018 \\
\hline & & MVI-W" & 192 & 66 & & 48 & & \\
\hline \multirow[t]{2}{*}{ Hwang et al. (31) } & NA & $\mathrm{NVI}$ & 1720 & 80.9 & $<0.001$ & 47.1 & $<0.001$ & 2015 \\
\hline & & MVI & 236 & 61.2 & & 30.9 & & \\
\hline \multirow[t]{2}{*}{ Banerjee et al. (44) } & NA & $\mathrm{NVI}$ & 111 & 78 & $<0.001$ & 61 & $<0.001$ & 2015 \\
\hline & & $\mathrm{MVI}$ & 44 & 55 & & 33 & & \\
\hline \multirow[t]{2}{*}{ Yamashita et al. (18) } & MPVI+MHVI+MBDI & $\mathrm{NVI}$ & 106 & 87 & 0.26 & 72 & $<0.001$ & 2012 \\
\hline & & MVI & 43 & 67 & & 44 & & \\
\hline \multirow[t]{2}{*}{ Lim et al. (14) } & NA & $\mathrm{NVI}$ & 197 & 61.3 & $<0.001$ & NA & NA & 2011 \\
\hline & & MVI & 44 & 36.6 & & NA & & \\
\hline
\end{tabular}

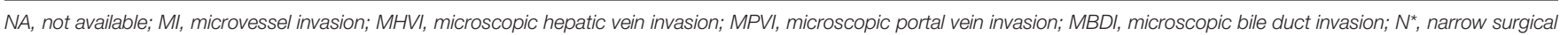
margin $<1 \mathrm{~cm}$; $W^{\#}$, wide surgical margin $\geq 1 \mathrm{~cm}$.

living donor LT, while $83 \%$ in patients with combined AFP $\leq 600$ $\mathrm{ng} / \mathrm{ml}$ and NVI $(p<0.001)$. Taken together, these findings indicated that MVI should be considered as a surgical contraindication to LT as it represented a waste of allografts. Conversely, a study from America evaluated the impact of MVI on prognosis of patients with $\mathrm{HCC} \leq 2 \mathrm{~cm}$ after LT; their results indicated that $\mathrm{HCC} \leq 2 \mathrm{~cm}$ had an excellent prognosis after LT and was not affected by the presence of MVI (67). Chan et al. (58) investigated the survival benefit of primary LT for HCC with MVI and within the up-to-7 criteria (7 as the sum of largest tumor diameter and tumor number). The 5-year OS rate was $85.7 \%$, and was not affected by the presence or absence of MVI (88.2\% vs. $85.1 \%)$. Therefore, the authors recommended that the presence of MVI should not be a contraindication to LT for HCC patients. It is worth noting that the definition of MVI was not recorded and small number of patients ( $n=23$ and $n=17)$ were MVIpositive, which may be the reason for this discrepancy with the previous studies.

In this regard, more accurate and simple definition of MVI will be needed for assessing the value of LT. Kang et al. (7) investigated whether classification of MVI affected the surgical outcomes after LT in HCC patients. The 5-year DFS rates were $89 \%, 67.9 \%$ and $0 \%$ in the NVI, MI and MPVI groups, respectively $(p<0.001)$, whereas the 5 -year OS rates were $79.1 \%, 55.0 \%$, and $15.4 \%$, respectively $(p<0.001)$. Accurate prediction of MVI before surgery can help liver surgeons to select suitable candidates for LT. When MPVI is predicted, the authors recommended that LT should not be pursued based on the poor surgical outcomes as determined by the classification system proposed (7). A recent study by Carr et al. (68) indicated that the mean overall survival of HCC patients with MPVI was significantly worse than those without MPVI (86.6 versus 110.5 months, $p=0.007)$. They further suggested that MPVI was associated with multiple tumor nodules, larger tumor size and higher serum levels of both AFP and gamma-glutamyl transpeptidase (GGT). Although LT for MVI-positive HCCs provides relative good prognosis, nevertheless, it's associated with poor surgical outcomes compared with other indications for LT. However, LT is still considered as first-line treatment for MVI-positive HCC patients due to the lack of accurate preoperative methods for the prediction of MVI. HCC patients with high-risk MVI waiting for LT may get benefit from preoperative neo-adjuvant treatment. A recent study demonstrated that bridging loco-regional therapy with Y-90 trans-arterial radio-embolization could reduce the incidence of MVI after LT and may improve tumor control and reduce postLT recurrence (69). Nevertheless, it needs to be further verified in randomized controlled trials.

It is of great importance to support post-LT surveillance for HCC recurrence, because early diagnosis and timely intervention may improve OS for HCC patients with MVI. Accordingly, liver surgeons attempted to find pre-operative biomarkers of MVI that predict recurrence and survival. Liver biopsy using fineneedle aspiration (FNA) could be one method to evaluate the MVI status of HCC patients on the waiting list. However, preoperative detection of MVI via biopsy was inaccurate due to intratumoral heterogeneity and sampling error $(41,70)$, and may increase the risk of tumor recurrence (64). Accordingly, there is an urgent need for a reliable non-invasive method to preoperatively detect the MVI status in the future. Studies which assessed the prognostic significance of MVI for long-term outcomes after LT are summarized in Table 2. It should be noted that the definition of MVI was not elaborated in nearly two-thirds of the studies (8/13). Therefore, the criteria for defining MVI are highly variable among these studies, which could affect the final results, thus, a consensus on defining MVI is necessary. 
MVI AND SELECTION OF SURGICAL TYPE

\section{AR or NAR}

Over the past few decades, debate about the superiority of AR compared with NAR for providing better surgical prognosis had never stopped. Previous studies demonstrated that AR obtained better OS and recurrence free survival (RFS) compared with non-anatomical resection (NAR) for HCC patients after LR (15, 71-77). Two recent meta-analyses demonstrated that AR seemed to offer better surgical outcomes versus NAR among HCC patients undergoing LR, especially for HCC patients without cirrhosis and small solitary tumors, although AR had similar perioperative morbidity and mortality versus $\operatorname{NAR}(78,79)$. However, other studies showed different results (80-84). A nationwide survey from Japan indicated that there was no significant difference in surgical outcomes after LR for solitary HCC between the AR and NAR groups, but the recurrence rates in the AR group were significantly better in HCC patients with a tumor diameter of 2 to $5 \mathrm{~cm}$ compared with those in the NAR group (85). Since HCC tumor cells are prone to spread through the portal venous system, theoretically, the AR method may prevent tumor cells spreading via portal vein invasion in HCC (75). Nevertheless, the effects and benefits of AR for HCC with MVI remain controversial $(15,76,82)$. For HCC patients with MVI which was defined as the presence of tumor cells in a portal vein, hepatic vein, or capsular vessel of the surrounding liver tissue lined by endothelium that was only visible microscopically, propensity score matching analysis was used to eliminate selection bias. AR significantly suppressed tumor recurrence after LR, whereas the OS rates were similar between the two groups $(15,22,86)$. Nonetheless, other studies failed to demonstrate these benefits when performing $\operatorname{AR}(8,18,82)$. The conflicting results were easy to understand because the OS of HCC patients was also affected by the tumor characteristics, hepatitis virus infection status and liver cirrhosis except surgical factors (87). In addition, it was noteworthy that the definitions of MVI were different, which may be responsible for the inconsistent conclusions. Yamashita et al. (18) evaluated the prognoses of HCC patients accompanied with micro-invasion (such as portal venous, hepatic vein or bile duct infiltration microscopically); the results indicated that there was no survival benefit of AR compared with NAR for patients with $\mathrm{HCC} \leq 2 \mathrm{~cm}$. Micro-metastases could spread via invasion of portal venous system and then develop to form microsatellite nodules even at an early stage (9). This suggested that AR was preferred for HCC patients with solitary tumor while NAR with adequate surgical margin could be used as an alternative treatment in HCC patients with limited liver function (51). Previous study showed that majority of classical HCCs have tumor capsules, making it seems impossible to be a microscopically positive surgical margin, although the surgical margin width was $0 \mathrm{~cm}$ when performing AR. However, NAR with a wide surgical margin will be needed for HCC patients aiming to preserve functional liver parenchyma as much as possible, especially in patients with liver cirrhosis (23). Unfortunately, this study did not consider the MVI status. For HCC patients with MVI, AR combined with a surgical margin $\geq 1 \mathrm{~cm}$ provided better surgical outcomes compared with NAR with surgical margin less than

TABLE 2 | MVI prognostic capability in HCC after liver transplantation.

\begin{tabular}{|c|c|c|c|c|c|c|c|c|}
\hline Author & Vascular type & MVI status & Number & 5-year OS(\%) & $p$-value & 5-year DFS(\%) & $p$-value & Published year \\
\hline \multirow[t]{3}{*}{ Kang et al. (7) } & $\mathrm{Ml}+\mathrm{MPVI}$ & $\mathrm{NVI}$ & 144 & 79.1 & $<0.001$ & 89 & $<0.001$ & 2020 \\
\hline & & $\mathrm{Ml}$ & 40 & 55 & & 67.9 & & \\
\hline & & MPVI & 13 & 15.4 & & 0 & & \\
\hline \multirow[t]{2}{*}{ Carr et al. (68) } & MPVI & $\mathrm{NVI}$ & 105 & 74.8 & $<0.001$ & NA & NA & 2020 \\
\hline & & MVI & 165 & 55.3 & & NA & & \\
\hline \multirow[t]{2}{*}{ Nitta et al. (33) } & $\mathrm{Ml}+\mathrm{MPVI}+\mathrm{MHVI}$ & $\mathrm{NVI}$ & 238 & 89.9 & $<0.001$ & 80.6 & $<0.001$ & 2019 \\
\hline & & MVI & 134 & 60.9 & & 51.4 & & \\
\hline \multirow[t]{2}{*}{ Choi et al. (63) } & NA & $\mathrm{NVI}$ & 184 & 87.1 & $<0.05$ & 76.8 & $<0.05$ & 2017 \\
\hline & & MVI & 24 & 64.5 & & 63.3 & & \\
\hline \multirow[t]{2}{*}{ Mohamed et al. (67) } & NA & $\mathrm{NVI}$ & 199 & 94 & 0.44 & NA & NA & 2017 \\
\hline & & $\mathrm{MVI}$ & 23 & 86 & & NA & & \\
\hline \multirow[t]{2}{*}{ Grąt et al. (62) } & NA & $\mathrm{NVI}$ & 143 & NA & NA & 85.9 & 0.001 & 2017 \\
\hline & & MVI & 57 & NA & & 55.3 & & \\
\hline \multirow[t]{2}{*}{ Donat et al. (64) } & NA & $\mathrm{NVI}$ & 110 & 69.9 & 0.007 & 59.5 & 0.003 & 2016 \\
\hline & & $\mathrm{MVI}$ & 41 & 48.4 & & 32 & & \\
\hline \multirow[t]{2}{*}{ Vilchez et al. (61) } & MPVI+MHVI & $\mathrm{NVI}$ & 73 & 68 & 0.001 & NA & NA & 2016 \\
\hline & & $\mathrm{MVI}$ & 22 & 52 & & NA & & \\
\hline \multirow[t]{2}{*}{ Agopian et al. (60) } & NA & $\mathrm{NVI}$ & 646 & NA & NA & 64 & $<0.001$ & 2015 \\
\hline & & $\mathrm{MVI}$ & 163 & NA & & 44 & & \\
\hline \multirow[t]{2}{*}{ Iguchi et al. (36) } & MPVI+MHVI & $\mathrm{NVI}$ & 87 & NA & NA & 87.5 & $<0.001$ & 2015 \\
\hline & & $\mathrm{MVI}$ & 38 & NA & & 42.6 & & \\
\hline \multirow[t]{2}{*}{ Moon et al. (59) } & NA & $\mathrm{NVI}$ & 112 & 90.5 & $<0.001$ & 95.3 & $<0.001$ & 2012 \\
\hline & & MVI & 74 & 58.2 & & 57.2 & & \\
\hline \multirow[t]{2}{*}{ Chan et al. (58) } & NA & $\mathrm{NVI}$ & 60 & 85.1 & NS & 86.4 & NS & 2012 \\
\hline & & $\mathrm{MVI}$ & 17 & 88.2 & & 88.2 & & \\
\hline \multirow[t]{2}{*}{ McHugh et al. (57) } & NA & $\mathrm{NVI}$ & 71 & 72 & 0.001 & NA & NA & 2010 \\
\hline & & MVI & 30 & 40 & & NA & & \\
\hline
\end{tabular}

NA, not available; NS, no significance. 
$1 \mathrm{~cm}(p=0.001)$, whereas AR was not necessary for HCC patients without MVI $(47,88)$. A multi-institutional study from Japan evaluated the value of AR for HCC with MPVI, the results demonstrated that there were no significant differences in longterm surgical outcomes between the AR and NAR groups using a propensity score-matched analysis (8). Especially, for tumors about 2 to $5 \mathrm{~cm}$ in size, AR still failed to gain a better OS or RFS than NAR, although the NAR group had higher proportions of hepatitis c virus (HCV), Child-Pugh class B, liver damage class B and worse ICG-R15 results than the AR group. A summary of studies in the past ten years which compared both recurrence and survival of surgical type (AR or NAR) for HCC patients with MVI are displayed in Table 3.

\section{Wide or Narrow Surgical Margin}

Whether surgical resection should be performed with wide or narrow surgical margin remains controversial in MVI-positive HCC patients. Several studies evaluated the relationship among surgical margin width, surgical outcomes and MVI status using measurement cut-offs for surgical margin width of $0.2,0.5$, and $1 \mathrm{~cm}(9,18,46,47)$. Since the incidence of MVI was correlated with tumor size, and MVI were reported to mainly present in the surgical margin adjacent to tumor, increased surgical margin width may improve surgical outcomes (31). Yamashita et al. (18) found that the presence of MVI was associated with poor surgical outcome in 5 -year DFS rate $(44 \%$ vs $72 \%, p<0.01)$ by evaluating 149 patients with surgically excised $\mathrm{HCC}<2 \mathrm{~cm}$ in diameter, however, this negative effect was neutralized with a wider surgical margin $(\geq 0.5 \mathrm{~cm})$. Wang et al. (46) evaluated the influence of surgical margin on the prognosis of patients with $\mathrm{HCC} \leq 5 \mathrm{~cm}$ and found that both the RFS and OS rates showed no significant difference in narrow $(\leq 0.2 \mathrm{~cm})$ and wide-margin $(>0.2 \mathrm{~cm}) \mathrm{LR}$ for the patients without MVI. However, for HCC patients with MVI, the narrow-margin LR showed poorer surgical outcomes than the wide-margin LR. The 1-, 3-, and 5-year RFS rates in the two groups were $63.3 \%, 32.8 \%$, and $25.4 \%$ versus $74.9 \%, 60.6 \%$, and $56.7 \%$, respectively $(p<0.001)$. The $1-, 3-$, and 5 -year OS rates in the two groups were $89.9 \%, 67.8 \%$, and $56.8 \%$ versus $97.1 \%, 84.2 \%$, and $76.3 \%$, respectively $(p=0.001)$. These studies indicated that a wider surgical margin could eliminate the peripheral intrahepatic micro-metastases, thus prevent early tumor recurrence. A recent study assessed the impact of hepatic surgical margin width on long-term outcomes for solitary HCC patients who underwent a negative margin curative LR. Margin width was categorized as "narrow" $(\leq 0.3 \mathrm{~cm})$, "intermediate" $(0.3-1.0 \mathrm{~cm})$, or "wide" $(>1.0 \mathrm{~cm})$, and there was no significant survival difference among the three groups regardless of MVI status. It should be noted that only $23.6 \%$ of HCC patients accompanied with MVI and nearly $70 \%$ of the patients underwent AR in this study, which may contribute to the better surgical outcomes. They recommended that narrow surgical margins seemed to be oncologically safe and the feasibility of achieving wide surgical margins should not be a determinant of resectability (89). The average tumor size was approximately $5.2 \mathrm{~cm}$ in this study, indicating that a wider surgical margin did not translate to better surgical outcomes for larger HCC patients with MVI, probably due to a greater burden of micro-metastases. However, another recent study indicated that more than $0.7-\mathrm{cm}$ surgical margin was important to prevent early recurrence among HCC patients with MVI, no tumor capsule and alpha-fetoprotein (AFP) levels $\geq 100 \mathrm{ng} / \mathrm{ml}$ (90). The reason for these inconsistent results may be partly due to different definitions of MVI and varied surgical margins. Actually, more than $80 \%$ of HCC patients that undergo LR are associated with liver cirrhosis in China (91, 92). For HCC patients with advanced liver cirrhosis, preserving adequate liver tissue is more important for surgical outcomes and it is less likely to undergo major surgical resection. Furthermore, the correlation between liver cirrhosis and MVI remains unclear. A summary of studies in the past ten years which evaluated the impact of surgical margin status on surgical outcomes for HCC patients with MVI are showed in Table 4.

Some authors emphasized the significance of the surgical margin width, arguing that AR was not necessarily needed when a wide and

TABLE 3 | MVI prognostic capability in HCC receiving AR or NAR.

\begin{tabular}{|c|c|c|c|c|c|c|c|c|}
\hline Author & Vascular type & Resection & Number & 5-year OS(\%) & p-value & 5-year DFS(\%) & p-value & Published year \\
\hline \multirow[t]{2}{*}{ Hidaka et al. (8) } & MPVI & $A R$ & 422 & 62.3 & NS & 38.2 & NS & 2020 \\
\hline & & NAR & 124 & 66.7 & & 36.6 & & \\
\hline \multirow[t]{2}{*}{ Hidaka et al. (8) } & MPVI & AR-PSM & 86 & 64.5 & NS & 37 & NS & 2020 \\
\hline & & NAR-PSM & 86 & 65.3 & & 42.2 & & \\
\hline \multirow[t]{2}{*}{ Shi et al. (22) } & $\mathrm{Ml}+\mathrm{MPVI}+\mathrm{MHVI}$ & $\mathrm{AR}$ & 118 & NA & NA & 45 & 0.001 & 2019 \\
\hline & & NAR & 113 & NA & & 20 & & \\
\hline \multirow[t]{2}{*}{ Zhong et al. (86) } & $\mathrm{Ml}+\mathrm{MPVI}+\mathrm{MHVI}$ & $\mathrm{AR}$ & 100 & 51.5 & 0.301 & 42 & 0.039 & 2019 \\
\hline & & NAR & 170 & 42.4 & & 26.4 & & \\
\hline \multirow[t]{2}{*}{ Zhao et al. (15) } & $\mathrm{Ml}+\mathrm{MPVI}+\mathrm{MHVI}$ & $\mathrm{AR}$ & 45 & 52 & 0.277 & 39 & 0.016 & 2017 \\
\hline & & NAR & 47 & 42 & & 20 & & \\
\hline \multirow[t]{2}{*}{ Matsumoto et al. (76) } & MPVI & AR & 74 & 46.1 & 0.002 & 33.8 & 0.001 & 2016 \\
\hline & & NAR & 23 & 16.3 & & 0 & & \\
\hline \multirow[t]{2}{*}{ Marubashi et al. (82) } & NA & $\mathrm{AR}$ & 110 & NA & NA & 50 & $0.312^{\#}$ & 2015 \\
\hline & & NAR & 83 & NA & & 43 & & \\
\hline \multirow[t]{2}{*}{ Yamashita et al. (18) } & MPVI+MHVI+MBDI & AR & 13 & 88 & 0.84 & 47 & 0.92 & 2012 \\
\hline & & NAR & 30 & 65 & & 23 & & \\
\hline
\end{tabular}

NA, not available; NS, no significance; AR, anatomical resection; NAR, non-anatomical resection; PSM, propensity score match.

\#2-year DFS. 
negative surgical margin can be obtained $(20,21,90)$. The impact of surgical margin width on long-term outcomes of HCC patients with MVI underwent LR has not been evaluated in relation to the type of LR performed. Our preliminary results indicated that 2-year recurrence rate in the MPVI group was significantly higher than that in the MI and NVI groups after LR ( $49.8 \%$ vs. $20.3 \%$ vs. $5.8 \%$, $p<0.01)$. HCC patients in MI group with a wide surgical margin $(\geq 1 \mathrm{~cm})$ showed better surgical outcomes than those with a narrow surgical margin $(<1 \mathrm{~cm})$. It was interesting to note that patients with MPVI experienced similar surgical outcomes irrespective of wide or narrow surgical margin. In addition, AR did not show better surgical outcomes after curative LR compared with NAR, which was consistent with previous results (8). Taken together with our experience and the results from previous studies, for HCC patients with MVI, AR or NAR and wide or narrow surgical margin should be performed individually. MVI should be sub-classified into MI and MPVI, for those HCC patients with MPVI, microvascular tumor thrombus at the transection site may disseminate to larger vessels via portal venous system and result in intrahepatic recurrence at a distance from the surgical margin in the remnant liver, which should be considered to be a systemic disease. Local resection with a wide or narrow surgical margin will get the same surgical results. However, for those HCC patients with MI which could be considered as a local disease, NAR with a wide and negative surgical margin will acquire relative better surgical outcomes (shown in Figure 1).

TABLE 4 | MVI prognostic capability in HCC with different width of surgical margin.

\begin{tabular}{|c|c|c|c|c|c|c|c|c|}
\hline Author & Vascular type & Surgical margin & Number & 5-year OS(\%) & $p$-value & 5-year DFS(\%) & $p$-value & Published year \\
\hline \multirow[t]{2}{*}{ Wang et al. (46) } & $\mathrm{Ml}+\mathrm{MPVI}+\mathrm{MHVI}$ & $\leq 0.2 \mathrm{~cm}$ & 130 & 56.8 & 0.01 & 25.4 & $<0.01$ & 2020 \\
\hline & & $>; 0.2 \mathrm{~cm}$ & 132 & 76.3 & & 60.6 & & \\
\hline \multirow[t]{2}{*}{ Han et al. (9) } & NA & $<1 \mathrm{~cm}$ & 158 & 55 & $<0.01$ & 30 & $<0.01$ & 2019 \\
\hline & & $\geq 1 \mathrm{~cm}$ & 192 & 66 & & 48 & & \\
\hline \multirow[t]{2}{*}{ Shi et al. (22) } & $\mathrm{Ml}+\mathrm{MPVI}+\mathrm{MHVI}$ & $\geq 1 \mathrm{~cm}$ & 105 & 50 & 0.01 & NA & 0.006 & 2019 \\
\hline & & $<1 \mathrm{~cm}$ & 126 & 25 & & NA & & \\
\hline \multirow[t]{2}{*}{ Yang et al. (47) } & $\mathrm{Ml}+\mathrm{MPVI}+\mathrm{MHVI}$ & $<1 \mathrm{~cm}$ & 545 & 25 & $<0.01$ & 14.1 & $<0.01$ & 2019 \\
\hline & & $\geq 1 \mathrm{~cm}$ & 384 & 44.9 & & 38.9 & & \\
\hline \multirow[t]{2}{*}{ Yamashita et al. (18) } & MPVI+MHVI+MBDI & $\geq 0.5 \mathrm{~cm}$ & 20 & 61 & 0.95 & 33 & 0.04 & 2012 \\
\hline & & $<0.5 \mathrm{~cm}$ & 23 & 73 & & 21 & & \\
\hline
\end{tabular}

NA, not available.

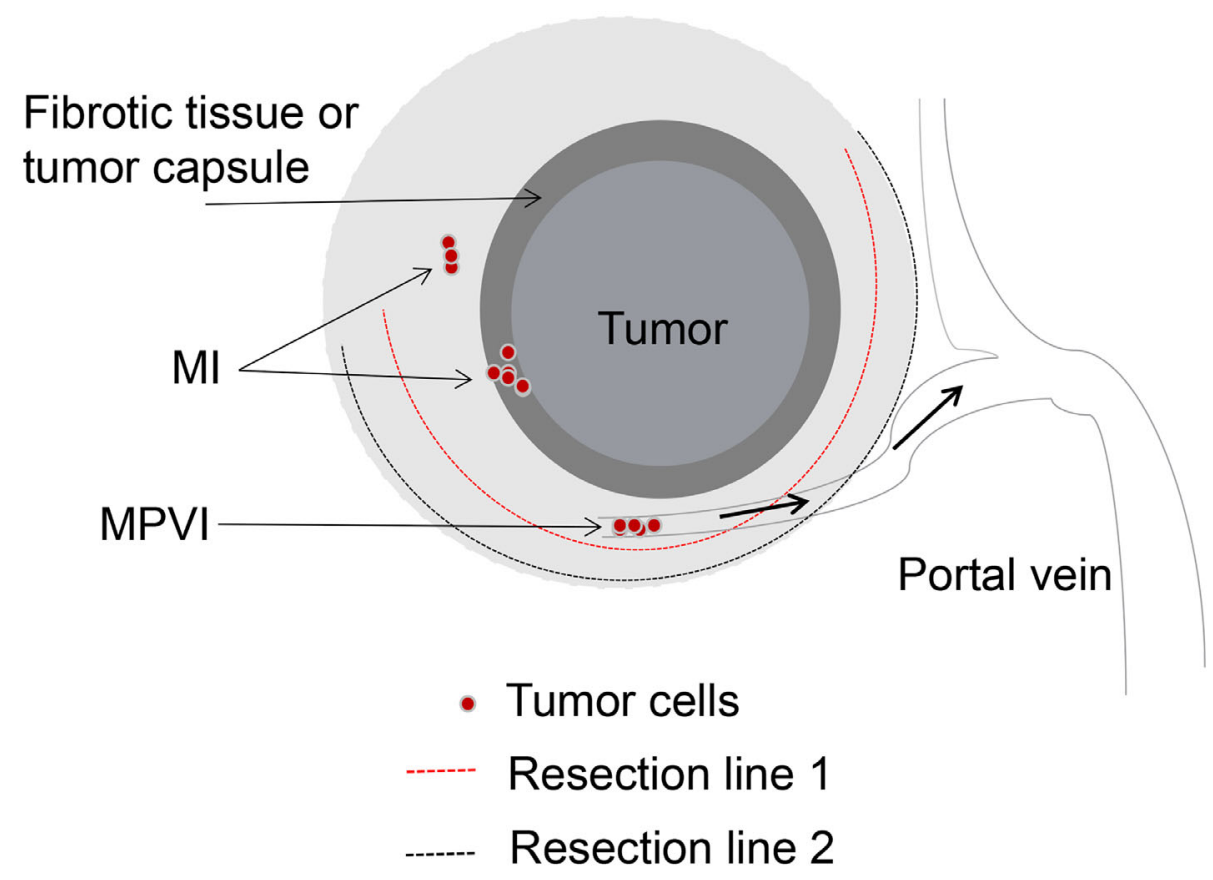

FIGURE 1 | Surgical strategy of LR based on the sub-classification of MVI. MI, Tumor cells in the microvascular space of the tumor capsule or compressed and fibrotic liver tissue, adjacent to the tumor mass. MPVI, Tumor cells in the portal vein, away from the tumor mass. Both of resection line 1 and 2 could completely remove the tumor and tumor vascular invasion for patients with Ml, however, it's unavailable for patients with MPVI. 


\section{CONCLUSION}

The presence of MVI is highly associated with adverse biological tumor behavior in HCC and is a critical determinant of HCC recurrence after LR or LT. Surgical outcomes of HCC patients with MVI have been described as a varied range after curative therapies due to the broad spectrum of current definitions for MVI. An international consensus on the validated definition of MVI in HCC is urgently needed which may provide a more consistent assessment and reliable prediction of surgical outcomes for HCC patients after curative treatments. MVI should be further sub-classified into MI and MPVI, for HCC patients with MPVI, local R0 resection with a narrow or wide surgical margin will get the same surgical results. However, for HCC patients with MI, local surgical resection with a wide and negative surgical margin will acquire better surgical outcomes. Unfortunately, MVI can only be precisely identified according to the postoperative examination of surgical specimens, limiting its potential value in guiding the personalized therapy. In the recent years, with the development of imaging technologies, application of axial imaging using CT, MRI, and PET/CT together with the novel serum biomarkers and molecular characterization of biopsy tissue provided more reliable methods for preoperatively predicting MVI status. Precise preoperative measurement of MVI is urgently needed, as it is helpful to select a reasonable

\section{REFERENCES}

1. Bertuccio P, Turati F, Carioli G, Rodriguez T, La Vecchia C, Malvezzi M, et al. Global Trends and Predictions in Hepatocellular Carcinoma Mortality. J Hepatol (2017) 67:302-9. doi: 10.1016/j.jhep.2017.03.011

2. Bray F, Ferlay J, Soerjomataram I, Siegel RL, Torre LA, Jemal A. Global Cancer Statistics 2018: GLOBOCAN Estimates of Incidence and Mortality Worldwide for 36 Cancers in 185 Countries. CA Cancer J Clin (2018) 68:394424. doi: $10.3322 /$ caac. 21492

3. Poon RT. Prevention of Recurrence After Resection of Hepatocellular Carcinoma: A Daunting Challenge. Hepatology (2011) 54:757-9. doi: 10.1002/hep.24569

4. Imamura H, Matsuyama Y, Tanaka E, Ohkubo T, Hasegawa K, Miyagawa S, et al. Risk Factors Contributing to Early and Late Phase Intrahepatic Recurrence of Hepatocellular Carcinoma After Hepatectomy. J Hepatol (2003) 38:200-7. doi: 10.1016/s0168-8278(02)00360-4

5. Dhir M, Melin AA, Douaiher J, Lin C, Zhen WK, Hussain SM, et al. A Review and Update of Treatment Options and Controversies in the Management of Hepatocellular Carcinoma. Ann Surg (2016) 263:1112-25. doi: 10.1097/ SLA.0000000000001556

6. Rodriguez-Peralvarez M, Luong TV, Andreana L, Meyer T, Dhillon AP, Burroughs AK. A Systematic Review of Microvascular Invasion in Hepatocellular Carcinoma: Diagnostic and Prognostic Variability. Ann Surg Oncol (2013) 20:325-39. doi: 10.1245/s10434-012-2513-1

7. Kang I, Jang M, Lee JG, Han DH, Joo DJ, Kim KS, et al. Subclassification of Microscopic Vascular Invasion in Hepatocellular Carcinoma. Ann Surg (2020). doi: 10.1097/SLA.0000000000003781

8. Hidaka M, Eguchi S, Okuda K, Beppu T, Shirabe K, Kondo K, et al. Impact of Anatomical Resection for Hepatocellular Carcinoma With Microportal Invasion (Vp1): A Multi-Institutional Study by the Kyushu Study Group of Liver Surgery. Ann Surg (2020) 271:339-46. doi: 10.1097/SLA. 0000000000002981

9. Han J, Li ZL, Xing H, Wu H, Zhu P, Lau WY, et al. The Impact of Resection Margin and Microvascular Invasion on Long-Term Prognosis After Curative Resection of Hepatocellular Carcinoma: A Multi-Institutional Study. HPB (Oxford) (2019) 21:962-71. doi: 10.1016/j.hpb.2018.11.005 surgical modality and greatly improve the surgical outcomes of HCC patients, especially in those with liver cirrhosis.

\section{AUTHOR CONTRIBUTIONS}

E-LZ and WD made the concept and design. QC drew the figure. E-LZ drafted the manuscript. Z-YH and WD critically revised the manuscript for the final version. All authors contributed to the article and approved the submitted version.

\section{FUNDING}

This work was supported by the grants from National Natural Science Foundation of China (81902839) and National Science and Technology Major Project of China (2017ZX10203207-002).

\section{ACKNOWLEDGMENTS}

Thanks to all the staff of Hepatic Surgery Center in Tongji Hospital who contributed to the study.

10. Roayaie S, Blume IN, Thung SN, Guido M, Fiel MI, Hiotis S, et al. A System of Classifying Microvascular Invasion to Predict Outcome After Resection in Patients With Hepatocellular Carcinoma. Gastroenterology (2009) 137:850-5. doi: 10.1053/j.gastro.2009.06.003

11. Zhang XP, Wang K, Wei XB, Li LQ, Sun HC, Wen TF, et al. An Eastern Hepatobiliary Surgery Hospital Microvascular Invasion Scoring System in Predicting Prognosis of Patients With Hepatocellular Carcinoma and Microvascular Invasion After R0 Liver Resection: A Large-Scale, Multicenter Study. Oncologist (2019) 24:e1476-88. doi: 10.1634/ theoncologist.2018-0868

12. Qiu J, Chen S, Wu H, Du C. The Prognostic Value of a Classification System for Centrally Located Liver Tumors in the Setting of Hepatocellular Carcinoma After Mesohepatectomy. Surg Oncol (2016) 25:441-7. doi: 10.1016/j.suronc.2016.03.001

13. Mazzaferro V, Llovet JM, Miceli R, Bhoori S, Schiavo M, Mariani L, et al. Predicting Survival After Liver Transplantation in Patients With Hepatocellular Carcinoma Beyond the Milan Criteria: A Retrospective, Exploratory Analysis. Lancet Oncol (2009) 10:35-43. doi: 10.1016/S14702045(08)70284-5

14. Lim KC, Chow PK, Allen JC, Chia GS, Lim M, Cheow PC, et al. Microvascular Invasion is a Better Predictor of Tumor Recurrence and Overall Survival Following Surgical Resection for Hepatocellular Carcinoma Compared to the Milan Criteria. Ann Surg (2011) 254:108-13. doi: 10.1097/SLA. 0b013e31821ad884

15. Zhao H, Chen C, Gu S, Yan X, Jia W, Mao L, et al. Anatomical Versus nonAnatomical Resection for Solitary Hepatocellular Carcinoma Without Macroscopic Vascular Invasion: A Propensity Score Matching Analysis. J Gastroenterol Hepatol (2017) 32:870-8. doi: 10.1111/jgh.13603

16. Chun YS, Pawlik TM, Vauthey JN. 8th Edition of the AJCC Cancer Staging Manual: Pancreas and Hepatobiliary Cancers. Ann Surg Oncol (2018) 25:8457. doi: 10.1245/s10434-017-6025-x

17. Shindoh J, Andreou A, Aloia TA, Zimmitti G, Lauwers GY, Laurent A, et al. Microvascular Invasion Does Not Predict Long-Term Survival in Hepatocellular Carcinoma Up to $2 \mathrm{Cm}$ : Reappraisal of the Staging System for Solitary Tumors. Ann Surg Oncol (2013) 20:1223-9. doi: 10.1245/s10434012-2739-y 
18. Yamashita Y, Tsuijita E, Takeishi K, Fujiwara M, Kira S, Mori M, et al. Predictors for Microinvasion of Small Hepatocellular Carcinoma $</=2 \mathrm{Cm}$. Ann Surg Oncol (2012) 19:2027-34. doi: 10.1245/s10434-011-2195-0

19. Roayaie S, Obeidat K, Sposito C, Mariani L, Bhoori S, Pellegrinelli A, et al. Resection of Hepatocellular Cancer $</=2 \mathrm{Cm}$ : Results From Two Western Centers. Hepatology (2013) 57:1426-35. doi: 10.1002/hep.25832

20. Poon RT, Fan ST, Ng IO, Wong J. Significance of Resection Margin in Hepatectomy for Hepatocellular Carcinoma: A Critical Reappraisal. Ann Surg (2000) 231:544-51. doi: 10.1097/00000658-200004000-00014

21. Zhong FP, Zhang YJ, Liu Y, Zou SB. Prognostic Impact of Surgical Margin in Patients With Hepatocellular Carcinoma: A Meta-Analysis. Med (Baltimore) (2017) 96:e8043. doi: 10.1097/MD.0000000000008043

22. Shi C, Zhao Q, Liao B, Dong Z, Wang C, Yang J, et al. Anatomic Resection and Wide Resection Margin Play an Important Role in Hepatectomy for Hepatocellular Carcinoma With Peritumoural Micrometastasis. ANZ J Surg (2019) 89:E482-6. doi: 10.1111/ans.15396

23. Aoki T, Kubota K, Hasegawa K, Kubo S, Izumi N, Kokudo N, et al. Significance of the Surgical Hepatic Resection Margin in Patients With a Single Hepatocellular Carcinoma. Br J Surg (2020) 107:113-20. doi: 10.1002/ bjs.11329

24. Surov A, Pech M, Omari J, Fischbach F, Damm R, Fischbach K, et al. Diffusion-Weighted Imaging Reflects Tumor Grading and Microvascular Invasion in Hepatocellular Carcinoma. Liver Cancer (2021) 10:10-24. doi: 10.1159/000511384

25. Song L, Li J, Luo Y. The Importance of a Nonsmooth Tumor Margin and Incomplete Tumor Capsule in Predicting HCC Microvascular Invasion on Preoperative Imaging Examination: A Systematic Review and Meta-Analysis. Clin Imaging (2020) 76:77-82. doi: 10.1016/j.clinimag.2020.11.057

26. Zhou W, Jian W, Cen X, Zhang L, Guo H, Liu Z, et al. Prediction of Microvascular Invasion of Hepatocellular Carcinoma Based on ContrastEnhanced MR and 3D Convolutional Neural Networks. Front Oncol (2021) 11:588010. doi: 10.3389/fonc.2021.588010

27. Lim C, Salloum C, Chalaye J, Lahat E, Costentin CE, Osseis M, et al. 18f-Fdg PET/CT Predicts Microvascular Invasion and Early Recurrence After Liver Resection for Hepatocellular Carcinoma: A Prospective Observational Study. HPB (Oxford) (2019) 21:739-47. doi: 10.1016/j.hpb.2018.10.007

28. Reginelli A, Vacca G, Segreto T, Picascia R, Clemente A, Urraro F, et al. Can Microvascular Invasion in Hepatocellular Carcinoma be Predicted by Diagnostic Imaging? A critical review. Future Oncol (2018) 14:2985-94. doi: $10.2217 /$ fon-2018-0175

29. Cucchetti A, Piscaglia F, Grigioni AD, Ravaioli M, Cescon M, Zanello M, et al. Preoperative Prediction of Hepatocellular Carcinoma Tumour Grade and Micro-Vascular Invasion by Means of Artificial Neural Network: A Pilot Study. J Hepatol (2010) 52:880-8. doi: 10.1016/j.jhep.2009.12.037

30. Lei Z, Li J, Wu D, Xia Y, Wang Q, Si A, et al. Nomogram for Preoperative Estimation of Microvascular Invasion Risk in Hepatitis B Virus-Related Hepatocellular Carcinoma Within the Milan Criteria. JAMA Surg (2016) 151:356-63. doi: 10.1001/jamasurg.2015.4257

31. Hwang S, Lee YJ, Kim KH, Ahn CS, Moon DB, Ha TY, et al. The Impact of Tumor Size on Long-Term Survival Outcomes After Resection of Solitary Hepatocellular Carcinoma: Single-Institution Experience with 2558 Patients. J Gastrointest Surg (2015) 19:1281-90. doi: 10.1007/s11605-015-2849-5

32. Shirabe K, Toshima T, Kimura K, Yamashita Y, Ikeda T, Ikegami T, et al. New Scoring System for Prediction of Microvascular Invasion in Patients with Hepatocellular Carcinoma. Liver Int (2014) 34:937-41. doi: 10.1111/liv.12459

33. Nitta H, Allard MA, Sebagh M, Karam V, Ciacio O, Pittau G, et al. Predictive Model for Microvascular Invasion of Hepatocellular Carcinoma Among Candidates for Either Hepatic Resection or Liver Transplantation. Surgery (2019) 165:1168-75. doi: 10.1016/j.surg.2019.01.012

34. Wang H, Feng LH, Qian YW, Cao ZY, Wu MC, Cong WM. Does Microvascular Invasion in Barcelona Clinic Liver Cancer Stage A Multinodular Hepatocellular Carcinoma Indicate Early-Stage Behavior? Ann Transl Med (2019) 7:428. doi: 10.21037/atm.2019.08.114

35. Cong WM, Bu H, Chen J, Dong H, Zhu YY, Feng LH, et al. Practice Guidelines for the Pathological Diagnosis of Primary Liver Cancer: 2015 Update. World J Gastroenterol (2016) 22:9279-87. doi: 10.3748/wjg.v22.i42.9279

36. Iguchi T, Shirabe K, Aishima S, Wang H, Fujita N, Ninomiya M, et al. New Pathologic Stratification of Microvascular Invasion in Hepatocellular
Carcinoma: Predicting Prognosis After Living-Donor Liver Transplantation. Transplantation (2015) 99:1236-42. doi: 10.1097/TP.0000000000000489

37. Feng LH, Dong H, Lau WY, Yu H, Zhu YY, Zhao Y, et al. Novel Microvascular Invasion-Based Prognostic Nomograms to Predict Survival Outcomes in Patients After R0 Resection for Hepatocellular Carcinoma. J Cancer Res Clin Oncol (2017) 143:293-303. doi: 10.1007/s00432-016-2286-1

38. Zhao H, Chen C, Fu X, Yan X, Jia W, Mao L, et al. Prognostic Value of a Novel Risk Classification of Microvascular Invasion in Patients With Hepatocellular Carcinoma After Resection. Oncotarget (2017) 8:5474-86. doi: 10.18632/ oncotarget.12547

39. Sumie S, Nakashima O, Okuda K, Kuromatsu R, Kawaguchi A, Nakano M, et al. The Significance of Classifying Microvascular Invasion in Patients With Hepatocellular Carcinoma. Ann Surg Oncol (2014) 21:1002-9. doi: 10.1245/ s10434-013-3376-9

40. Fujita N, Aishima S, Iguchi T, Mano Y, Taketomi A, Shirabe K, et al. Histologic Classification of Microscopic Portal Venous Invasion to Predict Prognosis in Hepatocellular Carcinoma. Hum Pathol (2011) 42:1531-8. doi: 10.1016/j.humpath.2010.12.016

41. Erstad DJ, Tanabe KK. Prognostic and Therapeutic Implications of Microvascular Invasion in Hepatocellular Carcinoma. Ann Surg Oncol (2019) 26:1474-93. doi: 10.1245/s10434-019-07227-9

42. Kim JM, Kwon CHD, Joh JW, Na BG, Lee KW, Choi GS, et al. Nonanatomical Resection is Comparable With Anatomical Resection in Solitary Hepatocellular Carcinoma $<5 \mathrm{Cm}$ in the Right Posterior Section. Med (Baltimore) (2016) 95:e5382. doi: 10.1097/MD.0000000000005382

43. Song SK, Park MG, Park SK, Chung CW, Park Y. MicroRNAs Associated With Microvascular Invasion in Hepatocellular Carcinoma and Their Prognostic Impacts in Patients Undergoing Hepatic Resection. Oncol Lett (2019) 18:6293-303. doi: 10.3892/ol.2019.10987

44. Banerjee S, Wang DS, Kim HJ, Sirlin CB, Chan MG, Korn RL, et al. A Computed Tomography Radiogenomic Biomarker Predicts Microvascular Invasion and Clinical Outcomes in Hepatocellular Carcinoma. Hepatology (2015) 62:792-800. doi: 10.1002/hep.27877

45. Ng KK, Vauthey JN, Pawlik TM, Lauwers GY, Regimbeau JM, Belghiti J, et al. Is Hepatic Resection for Large or Multinodular Hepatocellular Carcinoma Justified? Results From a Multi-Institutional Database. Ann Surg Oncol (2005) 12:364-73. doi: 10.1245/ASO.2005.06.004

46. Wang H, Yu H, Qian YW, Cao ZY, Wu MC, Cong WM. Impact of Surgical Margin on the Prognosis of Early Hepatocellular Carcinoma $(</=5 \mathrm{Cm})$ : A Propensity Score Matching Analysis. Front Med (Lausanne) (2020) 7:139. doi: 10.3389/fmed.2020.00139

47. Yang P, Si A, Yang J, Cheng Z, Wang K, Li J, et al. A Wide-Margin Liver Resection Improves Long-Term Outcomes for Patients With HBV-related Hepatocellular Carcinoma With Microvascular Invasion. Surgery (2019) 165:721-30. doi: 10.1016/j.surg.2018.09.016

48. Wang CC, Iyer SG, Low JK, Lin CY, Wang SH, Lu SN, et al. Perioperative Factors Affecting Long-Term Outcomes of 473 Consecutive Patients Undergoing Hepatectomy for Hepatocellular Carcinoma. Ann Surg Oncol (2009) 16:1832-42. doi: 10.1245/s10434-009-0448-y

49. Shindoh J, Kobayashi Y, Kawamura Y, Akuta N, Kobayashi M, Suzuki Y, et al. Microvascular Invasion and a Size Cutoff Value of $2 \mathrm{Cm}$ Predict Long-Term Oncological Outcome in Multiple Hepatocellular Carcinoma: Reappraisal of the American Joint Committee on Cancer Staging System and Validation Using the Surveillance, Epidemiology, and End-Results Database. Liver Cancer (2020) 9:156-66. doi: 10.1159/000504193

50. Park S, Choi S, Cho YA, Sinn DH, Kim JM, Park CK, et al. Evaluation of the American Joint Committee on Cancer (AJCC) 8th Edition Staging System for Hepatocellular Carcinoma in 1,008 Patients With Curative Resection. Cancer Res Treat (2020) 52:1145-52. doi: 10.4143/crt.2020.208

51. Shi M, Zhang CQ, Zhang YQ, Liang XM, Li JQ. Micrometastases of Solitary Hepatocellular Carcinoma and Appropriate Resection Margin. World J Surg (2004) 28:376-81. doi: 10.1007/s00268-003-7308-x

52. Huang ZY, Liang BY, Xiong M, Dong KS, Zhang ZY, Zhang EL, et al. Severity of Cirrhosis Should Determine the Operative Modality for Patients With Early Hepatocellular Carcinoma and Compensated Liver Function. Surgery (2016) 159:621-31. doi: 10.1016/j.surg.2015.09.002

53. Goldberg D, Mantero A, Newcomb C, Delgado C, Forde KA, Kaplan DE, et al. Predicting Survival After Liver Transplantation in Patients With 
Hepatocellular Carcinoma Using the LiTES-HCC Score. J Hepatol (2021) S0168-8278(21)00004-0. doi: 10.1016/j.jhep.2020.12.021

54. Alver SK, Lorenz DJ, Marvin MR, Brock GN. Projected Outcomes of 6-Month Delay in Exception Points Versus an Equivalent Model for End-Stage Liver Disease Score for Hepatocellular Carcinoma Liver Transplant Candidates. Liver Transpl (2016) 22:1343-55. doi: 10.1002/lt.24503

55. Sha M, Tong Y, Xia Q. Living Donor Liver Transplantation for Patients With Hepatocellular Carcinoma: What are the Optimal Criteria? Liver Transpl (2021). doi: 10.1002/lt.26003

56. Bento de Sousa JH, Calil IL, Tustumi F, da Cunha Khalil D, Felga GEG, de Arruda Pecora RA, et al. Comparison Between Milan and UCSF Criteria for Liver Transplantation in Patients With Hepatocellular Carcinoma: A Systematic Review and Meta-Analysis. Transl Gastroenterol Hepatol (2021) 6:11. doi: $10.21037 / \operatorname{tgh} .2020 .01 .06$

57. McHugh PP, Gilbert J, Vera S, Koch A, Ranjan D, Gedaly R. AlphaFetoprotein and Tumour Size are Associated With Microvascular Invasion in Explanted Livers of Patients Undergoing Transplantation With Hepatocellular Carcinoma. HPB (Oxford) (2010) 12:56-61. doi: 10.1111/ j.1477-2574.2009.00128.x

58. Chan SC, Fan ST, Chok KS, Cheung TT, Chan AC, Fung JY, et al. Survival Advantage of Primary Liver Transplantation for Hepatocellular Carcinoma Within the Up-to-7 Criteria With Microvascular Invasion. Hepatol Int (2012) 6:646-56. doi: 10.1007/s12072-011-9318-3

59. Moon JI, Kwon CH, Joh JW, Choi GS, Jung GO, Kim JM, et al. Primary Versus Salvage Living Donor Liver Transplantation for Patients With Hepatocellular Carcinoma: Impact of Microvascular Invasion on Survival. Transplant Proc (2012) 44:487-93. doi: 10.1016/j.transproceed.2011.11.009

60. Agopian VG, Harlander-Locke M, Zarrinpar A, Kaldas FM, Farmer DG, Yersiz H, et al. A Novel Prognostic Nomogram Accurately Predicts Hepatocellular Carcinoma Recurrence After Liver Transplantation: Analysis of 865 Consecutive Liver Transplant Recipients. J Am Coll Surg (2015) 220:416-27. doi: 10.1016/j.jamcollsurg.2014.12.025

61. Vilchez V, Turcios L, Zaytseva Y, Stewart R, Lee EY, Maynard E, et al. Cancer Stem Cell Marker Expression Alone and in Combination With Microvascular Invasion Predicts Poor Prognosis in Patients Undergoing Transplantation for Hepatocellular Carcinoma. Am J Surg (2016) 212:238-45. doi: 10.1016/ j.amjsurg.2015.12.019

62. Grat M, Stypulkowski J, Patkowski W, Bik E, Krasnodebski M, Wronka KM, et al. Limitations of Predicting Microvascular Invasion in Patients With Hepatocellular Cancer Prior to Liver Transplantation. Sci Rep (2017) 7:39881. doi: 10.1038/srep39881

63. Choi HJ, Kim DG, Na GH, Hong TH, Bae SH, You YK, et al. The Clinical Outcomes of Patients With Portal Vein Tumor Thrombi After Living Donor Liver Transplantation. Liver Transpl (2017) 23:1023-31. doi: 10.1002/lt.24782

64. Donat M, Alonso S, Pereira F, Ferrero E, Carrion L, Acin-Gandara D, et al. Impact of Histological Factors of Hepatocellular Carcinoma on the Outcome of Liver Transplantation. Transplant Proc (2016) 48:1968-77. doi: 10.1016/ j.transproceed.2016.04.002

65. Aggarwal A, Te HS, Verna EC, Desai AP. A National Survey of Hepatocellular Carcinoma Surveillance Practices Following Liver Transplantation. Transplant Direct (2021) 7:e638. doi: 10.1097/TXD.0000000000001086

66. Bhatti ABH, Qureshi AI, Tahir R, Dar FS, Khan NY, Zia HH, et al. When to Call it Off: Defining Transplant Candidacy Limits in Liver Donor Liver Transplantation for Hepatocellular Carcinoma. BMC Cancer (2020) 20:754. doi: 10.1186/s12885-020-07238-w

67. El-Fattah MA. Hepatocellular Carcinoma Biology Predicts Survival Outcome After Liver Transplantation in the USA. Indian J Gastroenterol (2017) 36:11725. doi: 10.1007/s12664-017-0732-x

68. Carr BI, Ince V, Bag HG, Ersan V, Usta S, Yilmaz S. Microscopic Vascular Invasion by Hepatocellular Carcinoma in Liver Transplant Patients. Clin Pract (Lond) (2020) 17:1497-505.

69. Zori AG, Ismael MN, Limaye AR, Firpi R, Morelli G, Soldevila-Pico C, et al. Locoregional Therapy Protocols With and Without Radioembolization for Hepatocellular Carcinoma as Bridge to Liver Transplantation. Am J Clin Oncol (2020) 43:325-33. doi: 10.1097/COC.0000000000000678

70. Pawlik TM, Gleisner AL, Anders RA, Assumpcao L, Maley W, Choti MA. Preoperative Assessment of Hepatocellular Carcinoma Tumor Grade Using
Needle Biopsy: Implications for Transplant Eligibility. Ann Surg (2007) 245:435-42. doi: 10.1097/01.sla.0000250420.73854.ad

71. Hasegawa K, Kokudo N, Imamura H, Matsuyama Y, Aoki T, Minagawa M, et al. Prognostic Impact of Anatomic Resection for Hepatocellular Carcinoma. Ann Surg (2005) 242:252-9. doi: 10.1097/01.sla.0000171307.37401.db

72. Makuuchi M, Hasegawa H, Yamazaki S. Ultrasonically Guided Subsegmentectomy. Surg Gynecol Obstet (1985) 161:346-50. doi: 10.1055/s2007-1022639

73. Zhou Y, Xu D, Wu L, Li B. Meta-Analysis of Anatomic Resection Versus Nonanatomic Resection for Hepatocellular Carcinoma. Langenbecks Arch Surg (2011) 396:1109-17. doi: 10.1007/s00423-011-0784-9

74. Cucchetti A, Qiao GL, Cescon M, Li J, Xia Y, Ercolani G, et al. Anatomic Versus Nonanatomic Resection in Cirrhotic Patients With Early Hepatocellular Carcinoma. Surgery (2014) 155:512-21. doi: 10.1016/j.surg. 2013.10.009

75. Shindoh J, Makuuchi M, Matsuyama Y, Mise Y, Arita J, Sakamoto Y, et al. Complete Removal of the Tumor-Bearing Portal Territory Decreases Local Tumor Recurrence and Improves Disease-Specific Survival of Patients With Hepatocellular Carcinoma. J Hepatol (2016) 64:594-600. doi: 10.1016/ j.jhep.2015.10.015

76. Matsumoto T, Kubota K, Aoki T, Iso Y, Kato M, Shimoda M. Clinical Impact of Anatomical Liver Resection for Hepatocellular Carcinoma with Pathologically Proven Portal Vein Invasion. World J Surg (2016) 40:402-11. doi: 10.1007/s00268-015-3231-1

77. Jiao S, Li G, Zhang D, Xu Y, Liu J, Li G. Anatomic Versus non-Anatomic Resection for Hepatocellular Carcinoma, do We Have an Answer? A MetaAnalysis. Int J Surg (2020) 80:243-55. doi: 10.1016/j.ijsu.2020.05.008

78. Moris D, Tsilimigras DI, Kostakis ID, Ntanasis-Stathopoulos I, Shah KN, Felekouras E, et al. Anatomic Versus non-Anatomic Resection for Hepatocellular Carcinoma: A Systematic Review and Meta-Analysis. Eur J Surg Oncol (2018) 44:927-38. doi: 10.1016/j.ejso.2018.04.018

79. Tan Y, Zhang W, Jiang L, Yang J, Yan L. Efficacy and Safety of Anatomic Resection Versus Nonanatomic Resection in Patients With Hepatocellular Carcinoma: A Systemic Review and Meta-Analysis. PloS One (2017) 12: e0186930. doi: 10.1371/journal.pone.0186930

80. Kanematsu T, Takenaka K, Matsumata T, Furuta T, Sugimachi K, Inokuchi K. Limited Hepatic Resection Effective for Selected Cirrhotic Patients With Primary Liver Cancer. Ann Surg (1984) 199:51-6. doi: 10.1097/00000658198401000-00009

81. Kaibori M, Matsui Y, Hijikawa T, Uchida Y, Kwon AH, Kamiyama Y. Comparison of Limited and Anatomic Hepatic Resection for Hepatocellular Carcinoma With Hepatitis C. Surgery (2006) 139:385-94. doi: 10.1016/ j.surg.2005.08.035

82. Marubashi S, Gotoh K, Akita H, Takahashi H, Ito Y, Yano M, et al. Anatomical Versus non-Anatomical Resection for Hepatocellular Carcinoma. Br J Surg (2015) 102:776-84. doi: 10.1002/bjs.9815

83. Hirokawa F, Kubo S, Nagano H, Nakai T, Kaibori M, Hayashi M, et al. Do Patients With Small Solitary Hepatocellular Carcinomas Without Macroscopically Vascular Invasion Require Anatomic Resection? Propensity Score Analysis. Surgery (2015) 157:27-36. doi: 10.1016/j.surg.2014.06.080

84. Yamamoto Y, Ikoma H, Morimura R, Konishi H, Murayama Y, Komatsu S, et al. Clinical Analysis of Anatomical Resection for the Treatment of Hepatocellular Carcinoma Based on the Stratification of Liver Function. World J Surg (2014) 38:1154-63. doi: 10.1007/s00268-013-2369-y

85. Eguchi S, Kanematsu T, Arii S, Okazaki M, Okita K, Omata M, et al. Comparison of the Outcomes Between an Anatomical Subsegmentectomy and a non-Anatomical Minor Hepatectomy for Single Hepatocellular Carcinomas Based on a Japanese Nationwide Survey. Surgery (2008) 143:469-75. doi: 10.1016/j.surg.2007.12.003

86. Zhong XP, Zhang YF, Mei J, Li SH, Kan A, Lu LH, et al. Anatomical Versus Non-anatomical Resection for Hepatocellular Carcinoma With Microscope Vascular Invasion: A Propensity Score Matching Analysis. J Cancer (2019) 10:3950-7. doi: 10.7150/jca.32592

87. Huang G, Lau WY, Wang ZG, Pan ZY, Yuan SX, Shen F, et al. Antiviral Therapy Improves Postoperative Survival in Patients With Hepatocellular Carcinoma: A Randomized Controlled Trial. Ann Surg (2015) 261:56-66. doi: $10.1097 /$ SLA.0000000000000858 
88. Shi F, Zhou Z, Huang X, Liu Q, Lin A. Is Anatomical Resection Necessary for Early Hepatocellular Carcinoma? A Single Institution Retrospective Experience. Future Oncol (2019) 15:2041-51. doi: 10.2217/fon-2019-0117

89. Michelakos T, Kontos F, Sekigami Y, Qadan M, Cai L, Catalano O, et al. Hepatectomy for Solitary Hepatocellular Carcinoma: Resection Margin Width Does Not Predict Survival. J Gastrointest Surg (2020). doi: 10.1007/s11605020-04765-6

90. Nitta H, Allard MA, Sebagh M, Golse N, Ciacio O, Pittau G, et al. Ideal Surgical Margin to Prevent Early Recurrence After Hepatic Resection for Hepatocellular Carcinoma. World J Surg (2021) 45:1159-67. doi: 10.1007/ s00268-020-05881-9

91. Zhang B, Zhang B, Zhang Z, Huang Z, Chen Y, Chen M, et al. 42,573 Cases of Hepatectomy in China: A Multicenter Retrospective Investigation. Sci China Life Sci (2018) 61:660-70. doi: 10.1007/s11427-017-9259-9
92. Zhang EL, Liang BY, Chen XP, Huang ZY. Severity of Liver Cirrhosis: A Key Role in the Selection of Surgical Modality for Child-Pugh A Hepatocellular Carcinoma. World J Surg Oncol (2015) 13:148. doi: 10.1186/s12957-015-0567-9

Conflict of Interest: The authors declare that the research was conducted in the absence of any commercial or financial relationships that could be construed as a potential conflict of interest.

Copyright (C) 2021 Zhang, Cheng, Huang and Dong. This is an open-access article distributed under the terms of the Creative Commons Attribution License (CC BY). The use, distribution or reproduction in other forums is permitted, provided the original author(s) and the copyright owner(s) are credited and that the original publication in this journal is cited, in accordance with accepted academic practice. No use, distribution or reproduction is permitted which does not comply with these terms. 